\title{
Quantitative Resistance Loci to Southern Rust Mapped in a Temperate Maize Diversity Panel
}

\author{
Guangchao Sun, ${ }^{1,2,3, \dagger}$ Ravi V. Mural, ${ }^{1,2,3}$ Jonathan D. Turkus, ${ }^{1,2,3}$ and James C. Schnable ${ }^{1,2,3, \dagger}$ \\ ${ }^{1}$ Quantitative Life Sciences Initiative, University of Nebraska-Lincoln, Lincoln, NE 68588 \\ ${ }^{2}$ Center for Plant Science Innovation, University of Nebraska-Lincoln, Lincoln, NE 68588 \\ ${ }^{3}$ Department of Agronomy and Horticulture, University of Nebraska-Lincoln, Lincoln, NE 68588 \\ Accepted for publication 18 July 2021.
}

\begin{abstract}
Southern rust is a severe foliar disease of maize (Zea mays) resulting from infection with the obligate biotrophic fungus Puccinia polysora. This disease reduces photosynthetic productivity, which in turn reduces yields, with the greatest yield losses (up to 50\%) associated with earlier onset infections. P. polysora urediniospores overwinter only in tropical and subtropical regions but cause outbreaks when environmental conditions favor initial infection. Increased temperatures and humidity during the growing season combined with an increased frequency of

studies identified four loci associated with significant quantitative variation in disease severity. These loci were associated with candidate genes with plausible links to quantitative disease resistance. A transcriptomewide association study identified additional genes associated with disease severity. Together, these results indicate that substantial diversity in resistance to southern rust exists among current temperate-adapted maize germplasm, including several candidate loci that may explain the observed variation in resistance to southern rust.
\end{abstract} moderate winters are likely to increase the frequency of severe southern rust outbreaks in the U.S. Corn Belt. In summer 2020, a severe outbreak of southern rust was observed in eastern Nebraska, United States. We scored a replicated maize association panel planted in Lincoln, NE for disease severity and found that disease incidence and severity showed significant variation among maize genotypes. Genome-wide association
Keywords: bioinformatics, disease resistance, expression quantitative trait loci mapping, fungal pathogens, genome-wide association study, genomics, Puccinia polysora, quantitative disease resistance, Southern corn rust, transcriptome-wide association study
Southern rust is a foliar disease resulting from infection with the fungus Puccinia polysora that infects corn (Zea mays) throughout the world. The greatest yield losses are observed in tropical and semitropical regions. In the north-central United States, southern rust outbreaks are infrequent, as the spores cannot overwinter in this region. However, when an outbreak occurs, sometimes after a moderate winter, yield losses can be substantial, as temperate maize germplasm predominantly lacks both qualitative and quantitative resistance to southern rust (Brewbaker et al. 2011). Yield losses of 138 million bushels were attributed to an outbreak of southern rust in the northern United States and Canada in 2016, and 93 million bushels of lost yield occurred in the same region in 2017 (Mueller et al. 2020). Yet outbreaks of southern rust can be much worse. In the 1950s, southern rust reached Africa, where the maize varieties now being grown lacked resistance to the pathogen, and yield losses of $50 \%$ were observed across large regions (Rhind et al. 1952). In controlled inoculation studies, maize yields were reduced by $39 \%$ in response to inoculation with $P$. polysora in Maryland

${ }^{\dagger}$ Corresponding authors: G. Sun; gsun2@unl.edu, and J. C. Schnable; schnable@unl.edu

Funding: This work was supported by the U.S. National Science Foundation under grant OIA-1557417, the Foundation for Food and Agriculture Research under grant 602757, and the U.S. Department of Energy Advanced Research Projects Agency-Energy under contract 18/CJ000/01/0.

*The $e$-Xtra logo stands for "electronic extra" and indicates there are three supplementary data files, seven supplementary figures, and one supplementary table published online.

James C. Schnable has equity interests in Data2Bio, LLC; Dryland Genetics LLC; and EnGeniousAg LLC. He is a member of the scientific advisory board of GeneSeek and currently serves as a guest editor for The Plant Cell.
(Raid et al. 1988). Comparisons of near-isogenic resistant and susceptible hybrids in Mississippi indicated that southern rust could reduce yields by up to $45 \%$ (Rodriguez-Ardon et al. 1980), with the severity of the losses depending on how early in its lifecycle the corn field is exposed to southern rust infection.

The first reported observation of southern rust was on Tripsacum dactyloides, a wild relative of maize, outside Auburn, Alabama in 1891 (Underwood 1897). However, the pathogen was likely widespread in central and southern America by 1879 (Cummins 1941). $P$. polysora is cold-sensitive and cannot overwinter in the United States. The severity of southern rust outbreaks in the northern United States depends on how far south the urediniospores of the pathogen died off in the previous winter, how quickly urediniospores produced in the south blow northwards, and how rapidly the urediniospores are able to initiate infection based on environmental conditions (Mueller et al. 2018). Given the decreasing severity of winters in the temperate United States, it is likely that southern rust outbreaks in the northern United States will become more common and more severe in the coming years.

Southern rust can be controlled by a range of fungicides (Mueller et al. 2018). However, the most economical and sustainable approach to mitigating yield losses is the development and commercialization of resistant maize lines. A number of resistance loci have been reported in both temperate and tropical germplasm, with many mapped resistance loci clustering on the short arm of chromosome 10, some or all of which might represent alleles of the same locus (Brewbaker et al. 2011; Wu et al. 2015). The RPP9 locus on chromosome 10 was originally identified in Boesman Yellow Flint, a maize line collected in South Africa (Ullstrup et al. 1965). In the 1990s, commercial hybrids were released in the United States with resistance to a prevalent strain of southern rust (Holland et al. 1998). By 2009, southern rust infections were reported in lines carrying the $R P P 9$ locus after southern rust had been successfully controlled for 30 years, pointing to the 
breakdown of resistance conferred by this locus (Brewbaker et al. 2011; Dolezal et al. 2009; Storey and Howland 1959). The potential for the breakdown of resistance is a major downside of qualitative resistance genes. By contrast, the outcomes of the majority of host-pathogen interactions are determined by quantitative resistance mechanisms, which are less susceptible to breakdown but are also less amenable to genetic investigation and incorporation into breeding programs (Corwin and Kliebenstein 2017).

A number of reports of quantitative resistance to southern rust exist in the literature. Holland et al. (1998) mapped quantitative resistance loci in F2-derived F3 populations. In addition to the widely reported large-effect loci on the short arm of chromosome 10, two smaller-effect quantitative trait loci (QTLs) were also identified on chromosomes 3 and 4, with each explaining approximately $14 \%$ of the total variation in southern rust resistance. In addition, Jiang et al. (1999) reported QTLs on chromosomes 3, 4, and 9; Brunelli et al. (2002) identified a QTL on chromosomes 9; Jines et al. (2007) mapped QTLs on chromosomes 4, 8, 9, and 10; Brewbaker et al. (2011) mapped a QTL on chromosome 6; and Wanlayaporn et al. (2013) reported six QTLs for resistance on chromosomes 1, 2, 5, 6, 9, and 10. These studies in aggregate demonstrate that both qualitative and quantitative southern rust resistance loci exist within maize germplasm. However, these studies primarily utilized biparental populations which, while increasing the power to detect segregating variation, provide a limited amount of insight into the overall genetic architecture of quantitative resistance to southern rust in temperate maize.

A severe outbreak of southern rust in eastern Nebraska occurred during the 2020 growing season (Corn ipmPIPE 2020; JacksonZiems 2020), providing us with the opportunity to screen a preexisting maize experiment constituting 752 diverse genotypes grown in two independent replicated complete blocks for quantitative severity of southern rust infection. These genotypes were primarily drawn from temperate germplasm (Mazaheri et al. 2019) and hence, previously reported large-effect qualitative resistance loci such as $R P P 9$, which are almost exclusively drawn from tropical germplasm pools, are unlikely to be segregating in this population (Brewbaker et al. 2011). In this study, by employing a genotype dataset consisting of 2.7 million single-nucleotide polymorphism (SNP) markers with a minor allele frequency $>0.1$ generated from a combination of the published maize hapmap3 (Bukowski et al. 2018), deep resequencing data for the 509 Wisconsin Diversity Panel (Qiu et al. 2020), and RNA-seq data (Hirsch et al. 2014; Mazaheri et al. 2019), we sought to identify loci associated with quantitative resistance to southern rust using a combination of genome-wide association and transcriptome-wide association analysis.

\section{MATERIALS AND METHODS}

Field experiment and phenotyping. A set of 752 maize genotypes drawn from the set of 942 genotypes included in the Wisconsin Diversity Panel (Mazaheri et al. 2019) as well as integrated checks were planted in two independently replicated blocks at the Havelock Farm research facility of the University of Nebraska-Lincoln on 6 May 2020 (40.852 N, 96.616 W). Each replicate of genotypes was planted in two rows with 20 plants for each and was 7.5-feet long with 30-inch row spacing and 2.5-foot alleyways between sequential plots. Positions of the plots and the genotypes of the plots were included in Supplementary Data File S1. Significant southern rust infection was observed on 14 August 2020. Scoring for southern corn rust disease severity was conducted on 19 August 2020. The severity of rust was assessed by three individuals (P1, P2, and P3) using a five-point rating scale with 0.0 being completely free of southern rust and 4.0 being the most susceptible (Zhao et al. 2013). Two representative plants randomly selected from different rows were scored for each plot. The mean scores of the two plants were calculated to indicate the disease severity of that plot. To assess and correct for individual specific biases in scoring, a subset of 336 plots was selected and scored by all three individuals (Supplementary Data File S1). The plots that died, desiccated, or lodged were skipped for disease severity scoring.

Using the row and column coordinate of the control plots and southern rust disease severity by P1 and P3 as an independent variable, and disease severity scored by P3 as the dependent variable, we performed ordinary least square regression (OLS) implemented in the Python language (v.3.8) package statsmodels (https://www. statsmodels.org) to calculate the intercepts and coefficients of the row, column, and disease scores of the regression line used to predict P3 disease score by the corresponding dependent variables of all other plots (Supplementary Data Files S2 and S3). The resulting scores were then used for calculating genotype best linear unbiased predictors (BLUPs) for disease severity using the lme4 (v.1.1-26) package in R (v.4.0.2; Bates et al. 2018), genotype and scorers were fitted in the model as one of the random effects: model = MeanScore (1|Genotype) + (1|Scorer). After correction by regression, the "Scorer" variable explained less than one-half of $1 \%$ of the total variance.

Genotype dataset. High density genotyping was conducted using a set of 23,672,341 a priori segregating genetic markers from the Maize HapMap3 dataset (Bukowski et al. 2018). A set of 129 lines overlapped between the HapMap3 dataset and the 942 lines of the Wisconsin diversity panel. For the remaining lines, a priori were scored using published resequencing data (452 genotypes taken from Qiu et al. 2020) or published RNA-seq data (361 lines taken from Mazaheri et al. 2019 or Hirsch et al. 2014).

Sequence data were first trimmed using the tool Trimmomatic (v.0.33; http://www.usadellab.org/cms/?page=trimmomatic) with the parameter settings as follows: "phred33 LEADING:3 TRAILING:3 slidingwindow:4:15 MINLEN:36 ILLUMINACLIP:TruSeq3-PE.fa: 2:30:10" (Bolger et al. 2014). The resulting trimmed reads were mapped to the B73 RefGen_v4 maize genome assembly (Jiao et al. 2017; Schnable et al. 2009) using the program BWA-MEM (v.0.7) with default parameter settings (Li 2013). Duplicated reads resulting from PCR amplification were marked using the program Picard (v.2.22; http://broadinstitute.github.io/picard/). The resulting BAM files were used to call genotypes for the 23,672,341 a priori SNP sites using the GATK toolkit (v.5.1; McKenna et al. 2010). After genotyping, individuals with missing data were inputted with the program Beagle/v.5.01 (https://bio.tools/BEAGLE) with parameter settings ' window $=1$ overlap $=0.1$ ne $=1200$ ' with the entire HapMap3 population employed as a reference panel (Browning et al. 2018). Hapmap3 includes 83 million total variants (Bukowski et al. 2018). The subset of 23 million a priori SNP sites employed above was created by filtering the unimputed hapmap3 dataset downloadable from MaizeGDB (Lawrence et al. 2004). First, individuals with missing data rates $>0.6$ or an inbreeding coefficient $<0.9$ were removed. Second, individual markers among the remaining individuals with minor allele frequencies $<0.01$, or missing data rates $>0.6$, were removed. Then the remaining markers were inputted using Beagle/v.5.1 with the same parameter settings as given above (Browning et al. 2018). Finally, sites with heterozygosity rates $>0.2$ after imputation were removed, resulting in the final a priori segregating SNP dataset.

Genome-wide association analyses. For genome-wide association studies (GWAS), the initial SNP set was further filtered by the removal of SNPs with a minor allele frequency $\geq 0.1$ and SNPs with a heterozygous genotype call frequency $\leq 0.01$ across the 689 individuals, resulting in a set of 2,730,913 SNPs. Kinship matrices and the first five population-structure principal components were calculated from unlinked makers $\left(R^{2} \leq 0.2\right)$ using the program PLINK (v.1.9; Chang et al. 2015).

Two separate GWAS algorithms were employed: First, GWAS was conducted with the univariate mixed linear model, LMM, implemented in the program GEMMA (v.0.98.3) using the Kinship matrices and the first five principal components calculated from marker data to control the confounding effects of the population 
structure (Zhou and Stephens 2012). Second, GWAS was conducted using the FarmCPU algorithm (Liu et al. 2016), as implemented in the program rMVP (v.1.0.4; Yin et al. 2021). To estimate the stability of significant trait-associated SNPs (TASs) identified by FarmCPU, a resampling strategy was employed with the analysis run 100 times each with a different randomly selected subset of the 689 genotypes for which phenotypic and genotypic data were available (Huang et al. 2017; Wallace et al. 2016). Three population-structure principal components were calculated from the genotype data of the sampled population to control the population structure. Individual SNPs that were statistically significantly linked to the trait in question in $\geq 10$ of 100 resampling GWAS were considered as both statistically significant and stable TASs.

Expression QTL mapping. Published expression values (fragments per kilobase of exon per million mapped fragments [FPKM]) for annotated maize genes across the 689 genotypes with southern rust disease severity scores were retrieved from the literature (Gage et al. 2019; Hirsch et al. 2014; Mazaheri et al. 2019). These values were normalized via a Box-Cox transformation as described in Kremling et al. (2018). The tool matrixEQTL was used to conduct GWAS using the same set of SNP markers described above, and the normalized expression levels of each gene located within one megabase up or downstream of a TAS as individual molecular phenotypes (Shabalin 2012). The matrixEQTL analysis incorporated five principal components that had been used for GWAS in this study as covariates.

Transcriptome-wide association study. Tests for associations between transcript levels and disease severity scores were conducted for each of a set of 21,820 genes that were expressed at levels $>1$ FPKM in at least 345 of the 689 individuals scored for southern rust disease severity. Gene expression levels were treated as explanatory variables for southern rust severity score BLUPs. The association study was conducted by fitting the gene expression level as a random effect, and five genetic principal components and five expression principal components as fixed effects to control the population structures using the lme4 (v.1.1-26) package in the software environment R (v.4.0.2; Bates et al. 2018). $P$ values of genotype coefficients for each gene expression-disease severity score BLUP pair were ranked as references of association significance.

\section{RESULTS}

Observed distribution of southern rust severity in a maize diversity panel. We grew a set of 752 lines drawn from the predominantly temperate Wisconsin Diversity Panel (Hansey et al. 2011; Mazaheri et al. 2019) in a replicated design in a farm near Lincoln, NE (see "Materials and Methods"). On 14 August 2020, southern corn rust pustules were observed on the leaf surfaces of corn plants of multiple genotypes at the R1 to R4 stage (Fig. 1A). Based on the lifecycle of southern corn rust and southern corn rust tracker (Corn ipmPIPE 2020), the infection likely began in midJuly when the environment at the Nebraska field site was humid, with frequent rainfalls, and warm winds from the south may have carried a considerate number of spores into the region. On 19 August 2020, disease severity scores were obtained in the field by three individual scorers (designated P1, P2, and P3) using a published disease severity reference ranging from 0 (no disease) to 4 (high susceptibility; for raw scores, see Supplementary Data File S1; Zhao et al. 2013). Among the 1,680 plots representing 752 genotypes planted in two independently replicated blocks as part of the original field layout, 175 plots were severely lodged or had already senesced at the time of scoring. A total of 1,505 plots, representing one or more replicated plots for 689 genotypes were successfully scored. Each scorer was assigned partially overlapping sets of plots, resulting in the collection of 2,065 unique disease severity score data points (Supplementary Fig. S1). Individual scorers produced distinct medians and standard deviations for disease severity scores (Fig. 1B). To confirm that these ranges did not reflect spatial variation in disease severity among plots assigned to only one scorer, we conducted a comparison among plots assigned to all three scorers. Similar differences in median and standard deviation were observed (Fig. 1C). This significant human bias in the assignment of disease severity scores was consistent, yet at the same time, pairwise comparisons among scorers showed consistent correlations in the disease severity scores assigned to individual plots (Fig. 1D).

Correlations between the disease severity scores assigned to the same plots by P1 and P2 as well as P2 and P3 were greater than the correlations between disease severity scores assigned by $\mathrm{P} 1$ and P3. The P2 scores were more widely distributed across the entire scoring range. Using data on plots scored by all three individuals,
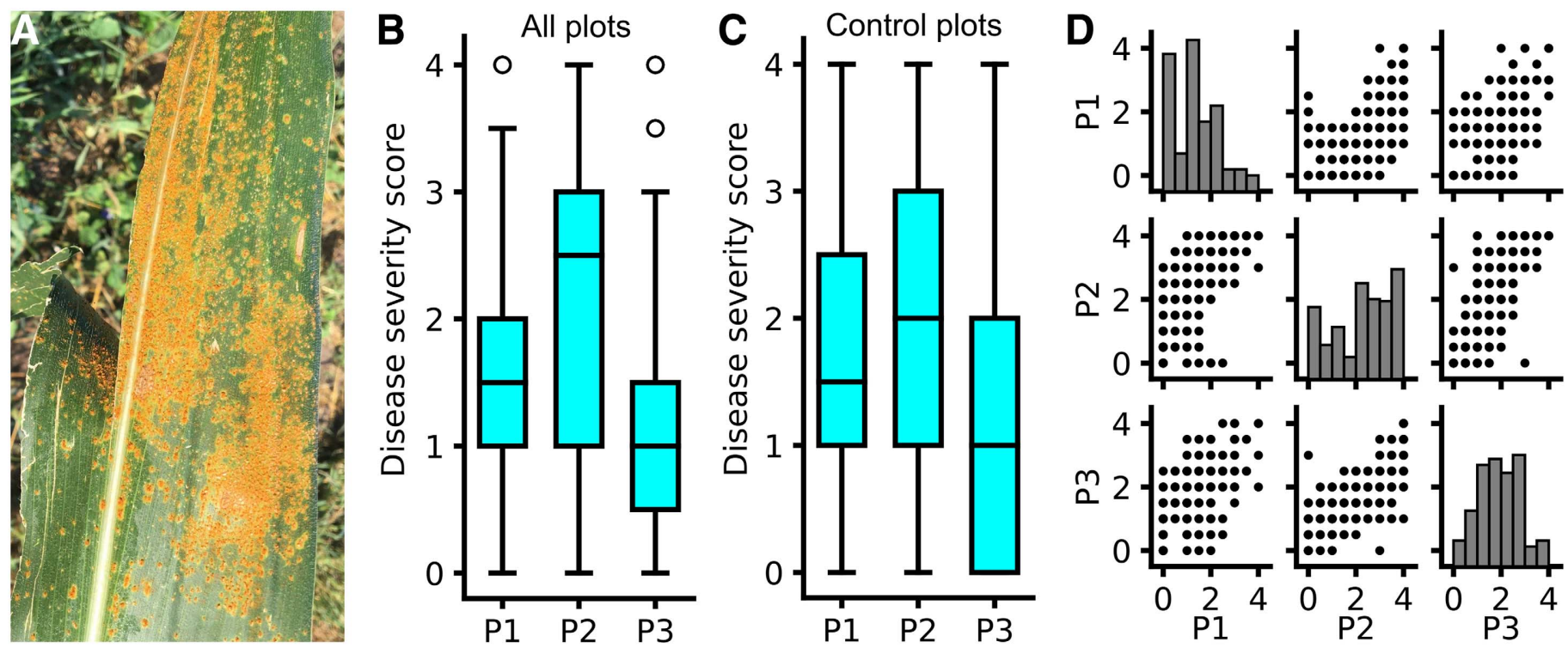

Fig. 1. Southern rust disease severity observed across an association panel in 2020. A, Example of an infected leaf from a susceptible maize line; the disease severity was scored as 4. B, Distribution of disease severity scores recorded by three different observers, P1 to P3, across the experiment (1,505 total plots). Not all plots were scored by each individual. C, Distribution of disease severity scores recorded by the same three observers on a set of 272 plots that were independently scored by each of the three individuals. D, Pair-wise comparison of the disease severity scores for the same plots obtained by the three scorers. Score distributions are shown on the diagonal. 
we conducted OLS regression analysis using either the P1 or P3 scores as independent variables, combined with spatial data, to predict the disease severity score that would have been assigned by P2 (response variable). The $R^{2}$ of the regression line between the raw disease severity scored by P1 and P2 was 0.443 , and that between P3 and P2 was 0.555. Regression-adjusted scores for P1 and P3 exhibited significant shrinkage toward the regression line but substantially standardized median and standard deviation in the raw scores (Fig. 2A and B). Compared with a broad sense heritability $\left(H^{2}\right)$ of 0.45 exhibited in raw disease severity scores, regressionadjusted scores exhibited a heritability of $H^{2}=0.56$ (for OLS regression results, see Supplementary Data Files S2 and S3). The 689 lines scored as part of this field included seven lines rated either 0 or 1 in a southern rust resistance screen of 1,890 diverse maize associations in Illinois using controlled inoculations of $P$. polysora (Chávez-Medina et al. 2007). Among overlapping lines identified as resistant ( 0 or 1$)$ in controlled inoculation studies, the average BLUP value assigned to a line in this study was 1.2 , with a maximum of 1.7 (Table 1). A maize inbred line from EX-PVP was originally reported to be susceptible to southern rust (Al Bari 2014) with a BLUP score of 2.7 , which is considered to be moderate susceptibility in this study.

Genomic loci linked to variation in southern corn rust disease severity. The heritability of the southern rust severity scores among the lines scored as part of this experiment suggested it might be possible to identify individual genetic loci that contribute to the observed severity of southern rust infections. Using a set of SNP markers generated from a combination of public resequencing experiments, maize HapMap, and RNA sequencing datasets (Bukowski et al. 2018; Hirsch et al. 2014; Mazaheri et al. 2019; Qiu et al. 2020), we conducted GWAS to detect potential genomic loci or features significantly associated with variation in southern rust severity. A total of six distinct peaks on chromosomes 2,4 (two peaks), 5, 6, and 7 that passed a suggestive $P$ value cutoff of $10 \mathrm{e}^{-5}$ was identified using GEMMA (Zhou and Stephens 2012).
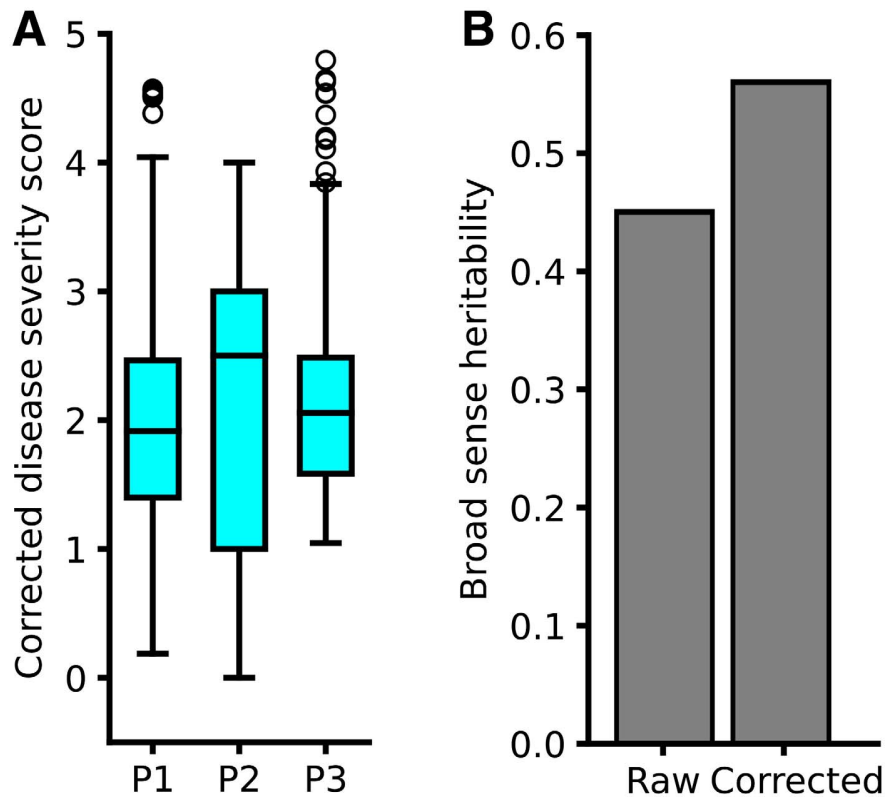

Fig. 2. Correcting for individual bias in disease severity scores. A, Distribution of disease severity scores after the raw scores for scorer 1 (P1) and scorer $3(\mathrm{P} 3)$ were replaced by predicted scores, as generated using a regression model trained to predict the values of scorer 2 with both human error and spatial effects incorporated ( $\mathrm{P} 2$ would assign scores to a given plot using the scores assigned by P1 or P3). B, Higher broad sense heritability was observed for scorer-bias-corrected disease severity scores $\left(H^{2}=0.56\right)$ than for raw values $\left(H^{2}=0.45\right)$.
The quantile-quantile plot for this analysis showed a significant deviation of $P$-values from the expected null model, suggesting that true positive signals were detected by GWAS (Supplementary Fig. S3). Of the six suggestive peaks, three were validated in $\geq 10 \%$ of FarmCPU resampling runs (Chr2:231,271,050, Chr4:78,851,667, and Chr4:173,863,109), and a fourth signal was detected (Chr6: $169,030,253)$ that did not correspond to a suggestive peak in the GEMMA results (Fig. 3A). The absolute values of estimated effect sizes for these four loci ranged from 0.122 to 0.167 (Fig. 3B), corresponding to an estimated difference in disease severity score between inbreds homozygous for different alleles of between 0.244 and 0.334 . The distributions of observed disease severity scores were notably different for each of the four loci, with the alternative alleles on chromosomes 2 and 6 associated with a decrease in southern rust severity and the alternative alleles of the two loci on chromosome 4 associated with an increase in southern rust severity (Fig. 3C).

Patterns of linkage disequilibrium (LD) vary throughout the maize genome, which can create challenges when attempting to link TASs to candidate genes. Except for the TAS Chr4:173,863,109, which was located within gene Zm00001d051893, the other three TASs were located outside of genes, with a distance to the first nearby gene of $30.8 \mathrm{~kb}$ for the TAS Chr2:231,271,050, $32.2 \mathrm{~kb}$ for the TAS Chr4:78,851,667 bp, and $1.6 \mathrm{~kb}$ for the TAS Chr6: 169,030,253 (Supplementary Table S1). We screened markers within one megabase flanking and in high linkage with each of the four TASs identified above. This analysis identified linked SNPs $\left(R^{2} \geq 0.8\right)$ for the TAS Chr2:231,271,050 spanning a 27-kb window where no gene resided, for the TAS Chr4:78,851,667 spanning a 1.4-kb window where no gene was located, for the TAS Chr4: $173,863,109$ spanning a $4.1-\mathrm{kb}$ window where gene Zm00001 d051893 resides, and for the TAS Chr6:169,030,253 spanning a 0.1-kb window where no gene resides (Supplementary Table S1).

Using publicly available expression data from maize seedlings, we conducted expression QTL (eQTL) analysis to identify cases where the TAS or another SNP in high LD with the TAS (LD $\geq$ 0.8 ) was, in turn, significantly associated with transcriptional variation of a gene, either inside or outside of the mapping interval defined by LD. A total of 12 potential cis-regulatory signals were linked with the four TASs either directly or indirectly via an SNP in high LD with the TAS. The variational expression level of a single nearby gene, Zm00001d007424, was significantly associated with the TAS Chr2:231,271,050 (Fig. 4A; Supplementary Fig. S4A). The TAS Chr4:78,851,667 was identified as a cis-eQTL of three genes: $\mathrm{Zm00001d050283,} \mathrm{Zm00001d050284,} \mathrm{and} \mathrm{Zm0000}$ 1d050293 (Fig. 4B; Supplementary Fig. S4B to D). The TAS Chr4: $173,863,109$ was identified as a cis-eQTL of two genes, Zm00001 d051914 and Zm00001d051893, and a SNP in high linkage with this TAS was identified as two other genes, Zm00001d051869 and Zm00001d05188 (Fig. 4C; Supplementary Fig. S4E and F). Similarly, the TAS Chr6:169,030,253 was identified as a cis-eQTL of two genes, Zm00001d039039 and Zm00001d039020, and an SNP in high linkage of this TAS was identified as a cis-eQTL of two additional genes: Zm00001d039004 and Zm00001d039043 (Fig. 4D; Supplementary Fig. S4G to I). For genes whose expression

TABLE 1. Southern rust scored in this study and in Chávez-Medina et al. (2007)

\begin{tabular}{|c|c|c|c|c|}
\hline Plot & Genotype & Mean score & BLUP $^{a}$ & $\begin{array}{l}\text { Chávez-Medina } \\
\text { et al. (2007) }\end{array}$ \\
\hline 2177 & Va59 & 0 & 0.86 & 0 \\
\hline 2219 & INBRED 2-687 & 0 & 1.13 & 0 \\
\hline 2633 & $\begin{array}{l}\text { INB 101LFY/LFY } \\
\text { (A632 X M16 S5) }\end{array}$ & 0.25 & 1.61 & 1 \\
\hline 2712 & Ку 228 & 0.25 & 1.05 & 1 \\
\hline
\end{tabular}

${ }^{\mathrm{a}}$ BLUP, best linear unbiased predictor. 
variation was directly associated with the four TASs, a consistent correlation (either negative or positive) was observed between expression level and disease severity, which could be distinguished based on the alleles of these four TASs (eQTLs; Supplementary Fig. S4).

Variation in southern corn rust disease severity is associated with variation in seedling transcript abundance. Transcriptome-wide association studies can play a complementary role to genome-wide studies by identifying genes that play important roles in determining phenotypic outcomes that are missed by the latter analysis (Kremling et al. 2019; Lin et al. 2017). Expression level data were generated for different subsets of the Wisconsin Diversity Panel as part of two published studies (Hirsch et al. 2014; Mazaheri et al. 2019). While batch effects exist between the two datasets (Supplementary Fig. S5), we incorporated both sets into the transcriptome-wide association study, with five expression level principal components incorporated as controls alongside five principal components calculated from genetic marker data (see Materials and Methods). The expression level of a single gene, Zm00001d035185, encoding an RNase E/G-like protein located on chromosome 6 at $8.6 \mathrm{MB}$, was significantly associated with variation in southern rust disease severity after correcting for multiple testing employing the Benjamini-Hochberg procedure (false discovery rate $\leq 0.05$; Supplementary Fig. S6A). Analysis of published expression datasets indicated that this gene is highly expressed in the leaves of maize throughout its entire lifecycle (Supplementary Fig. S7A). The next four most significantly associated genes, including Zm00001d050928 $(P=0.000021)$, Zm000$01 \mathrm{~d} 035195$ ( $P=0.000021), \mathrm{Zm00001 \textrm {d } 0 3 9 9 7 5}(P=0.000025)$, and Zm00001d013049 ( $P=0.000026)$, were also reported to be related to plant immune responses to pathogen infection (see Discussion; Supplementary Fig. S6B to E).
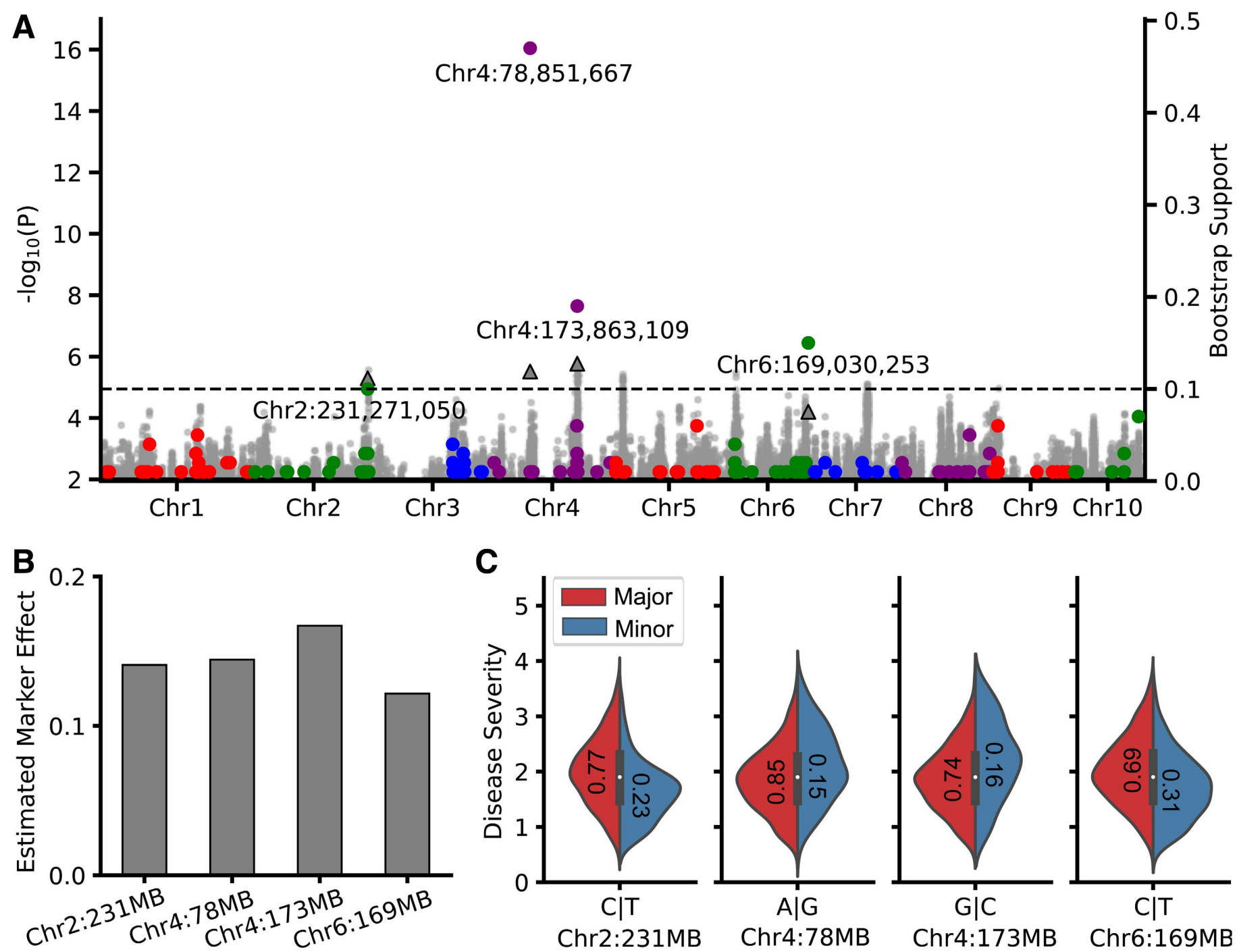

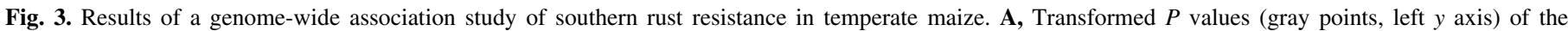

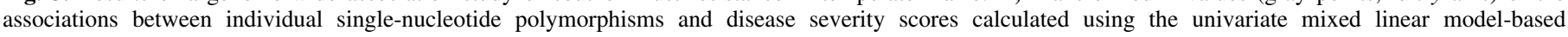

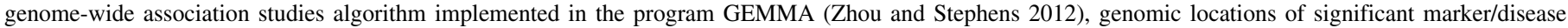

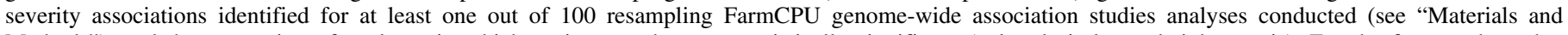

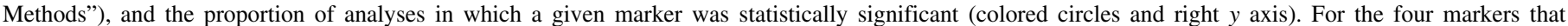

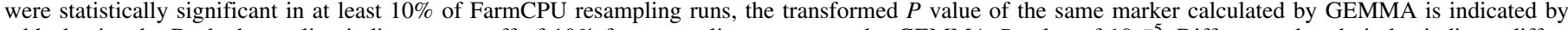

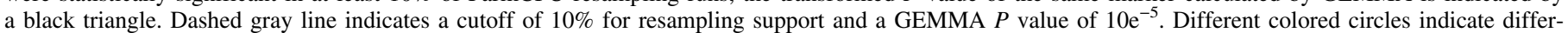

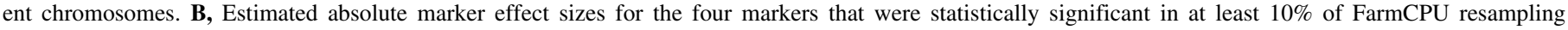

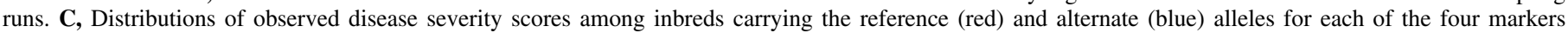

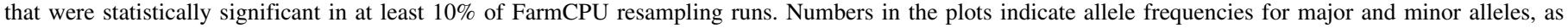
indicated. 


\section{DISCUSSION}

In this study, we took advantage of an unanticipated southern corn rust outbreak in eastern Nebraska during the 2020 growing season to assess the susceptibility or resistance of a set of 689 genotypes drawn from the Wisconsin Diversity Panel that were grown as part of a pre-existing experiment and had neither lodged nor senesced at the time of the outbreak. The scoring of disease severity by different individuals using a common ordinal scoring metric was known to generate differing distributions of disease severity, even when scoring identical plots (Poland and Nelson 2011). Designing scoring regimes must balance the desirability of minimizing variation resulting from greater numbers of scorers with minimizing variation resulting from scoring over multiple days. In this case, we adopted a three-scorer system, enabling all plots to be scored in a single day and minimizing the risk of large changes in apparent disease severity induced by rainfall washing off urediospores. Controlling for variability in the medians and distributions of assigned values between scorers substantially increased the overall heritability of the southern rust disease severity trait and enabled the identification of four statistically significant TASs and one statistically significant trait-associated transcript. Genetic loci associated with phenotypic variation can include upstream regulatory regions in only partial linkage with the coding sequence of the target gene. Notable examples include teosinte branched1, where the polymorphism responsible for the suppression of axillary branching is associated with a long range cis-regulatory element $60 \mathrm{~kb}$ upstream from the coding sequence (Studer et al. 2011; Tsiantis 2011); and vegetative to generative transition1, a major QTL regulating flowering time through variation in the expression of the gene ZmRap2.7,

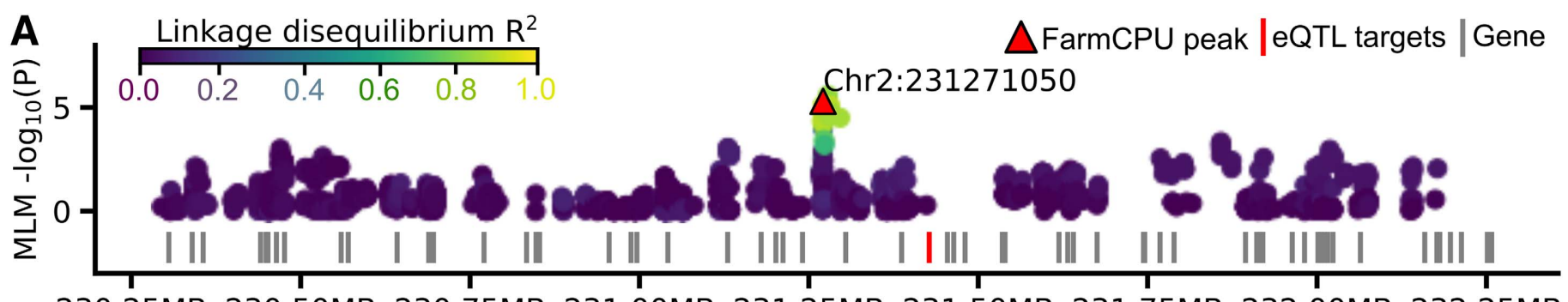

230.25MB 230.50MB 230.75MB 231.00MB 231.25MB 231.50MB 231.75MB 232.00MB 232.25MB

B Chromosome2
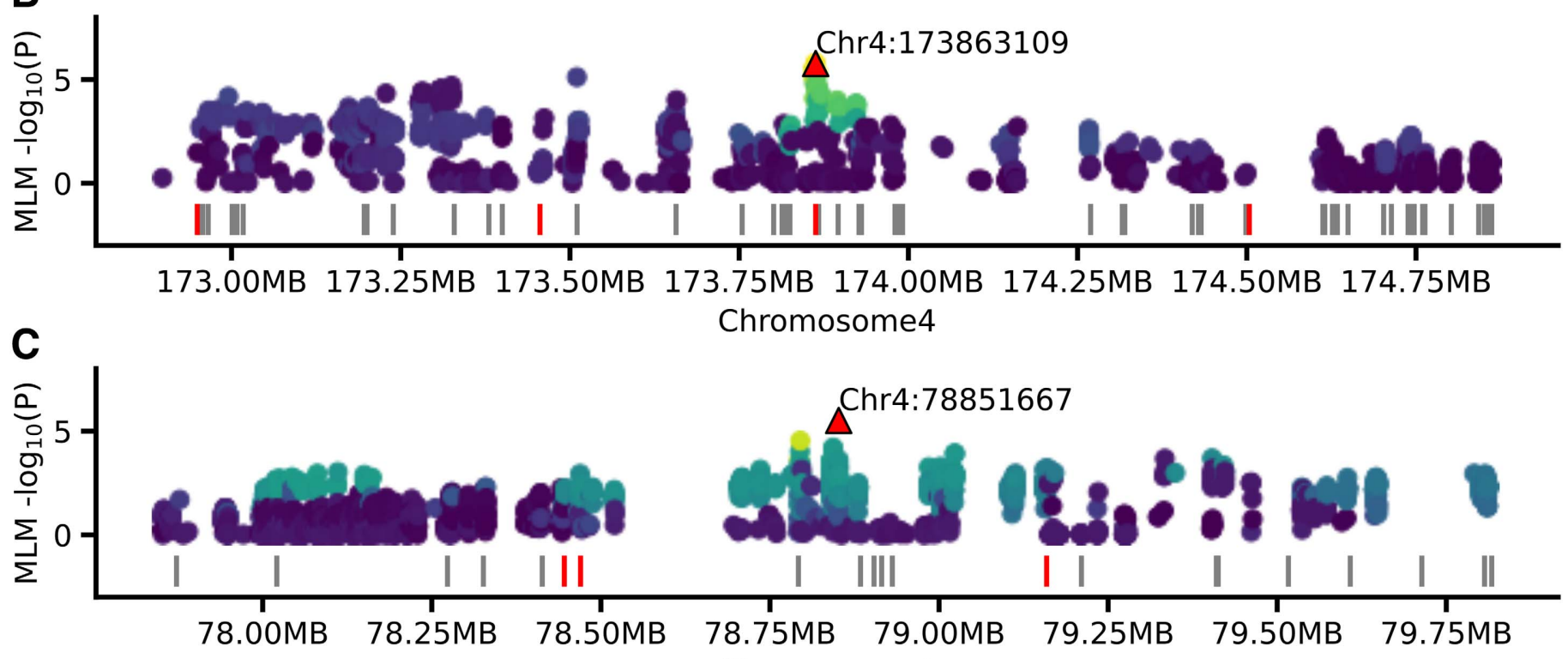

D

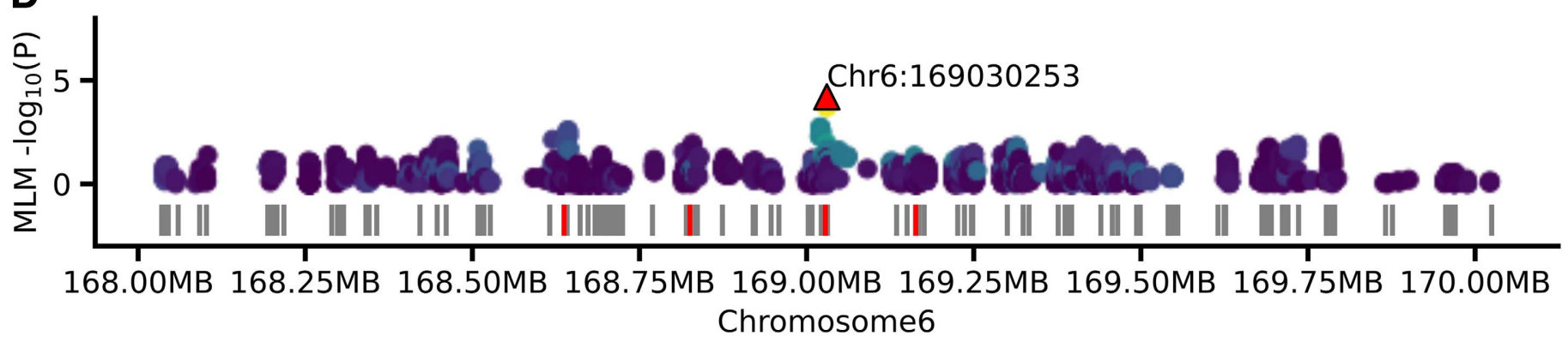

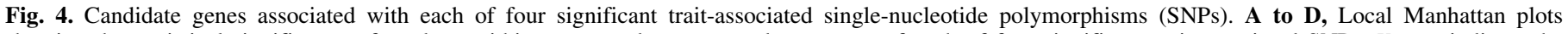

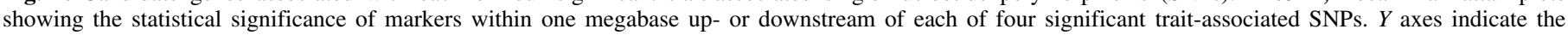

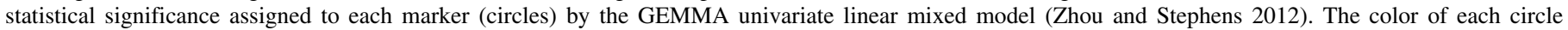

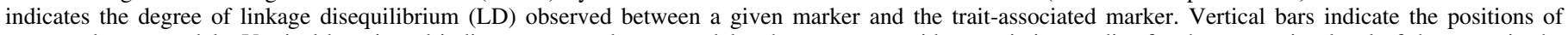

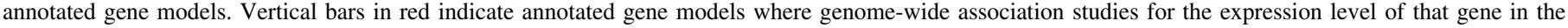
same population identified either the trait-associated SNP or an SNP in $\geq 0.8$ LD with the trait-associated SNP. MLM, mixed linear model. 
where the causal polymorphism was mapped to a conserved noncoding sequence $70 \mathrm{~kb}$ upstream (Castelletti et al. 2014; Salvi et al. 2002). We performed expression GWAS to identify sets of candidate genes whose expression levels were significantly associated with the TASs identified above.

Zm00001d007424, the only gene linked to the TAS on chromosome 2 via expression level variation, encodes long chain base biosynthesis protein1 ( $L C B 1)$. This protein, along with $L C B 2$, forms the heterodimer serine palmitoyltransferase, which catalyzes the first rate-limiting step of de novo sphingolipid synthesis (Fig. 4A). Loss of LCB1 has been shown to lead to the abolishment of programmed cell death initiated by the production of reactive oxygen intermediates (Shi et al. 2007). There has been a growing body of evidence supporting the notion that this sphingolipid-mediated programmed cell death is associated with plant immunity to pathogen infection, such as the maize pathogen Fusarium verticillioides and the tomato pathogen Alternaria alternata f. sp. lycopersici, as reviewed by Berkey et al. (2012).

Among the three genes (Zm00001d050283, Zm00001d050284, and $\mathrm{Zm00001d050293)} \mathrm{linked} \mathrm{to} \mathrm{the} \mathrm{TAS} \mathrm{Chr4:78,851,667} \mathrm{via}$ expression level variation, Zm00001d050283 was annotated to encode Sulfate transporter1.2. This sulfate transporter was highly conserved across eukaryotic kingdoms, and its homolog in tomato was highly expressed upon infection with the vascular pathogen Verticillium dahliae (Howarth et al. 2003). Zm00001d050284 was annotated as encoding a tRNA modification GTPase, trmE, which played a pivotal role in protein translation in plants. A natural loss-of-function variant allele of rice PLEIOTROPIC DEVELOPMENTAL DEFECTS, which encodes the same E family tRNA modification GTPase, has been shown to lead to a reduction in ribosome biogenesis and the levels of proteins related to photosynthesis, which could in turn affect leaf fitness (Liu et al. 2020). Zm00001d050293 encodes trehalose-6-phosphate synthase9, a key enzyme involved in trehalose-6-phosphate metabolism, which affects plant resilience (Paul et al. 2018) and immune responses to pathogen attack in tomato (Zhang et al. 2016).

Among the four genes linked to the TAS Chr4:173,863,109 identified via expression GWAS, Zm00001d051869 and Zm0000$1 \mathrm{~d} 051914$ have no annotation, Zm00001d051884 encodes a hydroxyproline-rich glycoprotein family protein, and $\mathrm{Zm0000-}$ $1 \mathrm{~d} 051893$ encodes a TPR-like superfamily protein associated with the disease response in plants. For example, $b s r-k 1$, a loss-of-function allele of rice TRP-domain RNA-binding protein $B S R-K 1$, rendered broad-spectrum disease resistance in rice (Zhou et al. 2018). Members of this TPR-like superfamily likely conferred disease resistance via a hormone-responsive mechanism. Notably, Zm00001d051893 was the only gene that was also linked to the TAS Chr4:173,863,109 directly (the SNP is located within the gene), or to SNPs in high LD with this TAS within the gene body (Fig. 4B).

Among the four genes (Zm00001d039004, Zm00001d0390020, Zm00001d039039, and Zm00001d039043) linked to the TAS Chr6:169,030,253 via either expression level variation or LD, Zm0001d039004 (NAC87) encodes a NAC-Type transcription factor reported to promote accumulation of reactive oxygen species, the hypersensitive response, and cell death in response to stress in oilseed rape (Brassica napus L.) (Yan et al. 2018). The downstream targets of this transcription factor included $R b o h B$ involved in reactive oxygen species production; cell death regulators VPE1a and ZEN1; WRKY6 and ZAT12 involved in leaf senescence; and commonly known plant disease resistance genes such as PR2 and PR5 (Yan et al. 2018). Zm00001d039039 encodes a chloroplastic Coldregulated 413 inner membrane protein2; Zm00001d039043 encoding Aspartic proteinase A1 likely involved in disease resistance. In Arabidopsis, an extracellular aspartic protease encoded by $C D R I$ led to dwarfing and resistance to virulent Pseudomonas syringae by activating micro-oxidative bursts and defense-related gene expression in a salicylic-acid-dependent manner (Xia et al. 2004).
It should be noted that this study was conducted using the B73 maize inbred reference genome. Maize exhibits substantial presence-absence variation (Hirsch et al. 2014; Springer et al. 2009; Swanson-Wagner et al. 2010). Therefore, the interpretation of candidate genes near TASs should include the context that individual TASs may reflect functional variation resulting from genes present in some maize haplotypes but absent from B73. Furthermore, we did not identify a significant signal at the location on chromosome 10 where RPP alleles were previously identified. This may reflect the absence or low allele frequency of southern corn rust resistance alleles at this locus in temperate germplasm, as RPP alleles on chromosome 10 have primarily been identified in tropical genetic backgrounds (Brewbaker et al. 2011; Jines et al. 2007; Ullstrup 1965; Wanlayaporn et al. 2013; Wu et al. 2015).

In addition to conventional GWAS, we also performed a parallel transcriptome-wide association study using data from maize seedlings grown under nonstressed conditions (Hirsch et al. 2014; Mazaheri et al. 2019). Gene expression data from one tissue type could be used to identify genetic loci in another tissue type ( $\mathrm{Li}$ et al. 2021), and we reasoned that gene expression data under one condition (uninfected seedlings) might also prove useful for identifying genes associated with phenotypic variation under another condition (southern rust infection in adult plants). The transcriptome-wide association study identified a single gene, Zm00001d035185, encoding an RNase E/G-like protein whose expression level in maize seedlings was significantly associated with variation in southern rust severity among adult maize plants (Supplementary Fig. S6).

Zm00001d035185 was highly expressed in leaves throughout the entire maize lifecycle (Supplementary Fig. S7A). The Arabidopsis homolog of Zm00001d035185, AT4G37920, was also expressed at high levels in leaves, and its encoded protein has been predicted to localize to guard cells (Supplementary Fig. S7B). Guard cells are known to be involved in pathogen recognition and immune responses, pointing to a plausible mechanism for the link between the expression of this gene and southern corn rust disease severity (David et al. 2019; Guimarães and Stotz 2004). In addition, the remaining four of the top five most significantly associated genes, while not individually passing stringent multiple testing correction, include several intriguing potential links to disease resistance. These genes, in order of decreasing statistical significance, include the following: Zm00001d050928 ( $P=0.000021)$, a gene with no functional annotation (Supplementary Fig. S6B); Zm00001d035195 $(P=0.000021)$, encoding a lysine-specific histone demethylase1 involved in plant growth, flowering time, hormone response, stress response, and circadian regulation (Clouse 1996; Krishna 2003; Luo et al. 2014; Supplementary Fig. S6C); Zm00001d039975 ( $P=$ $0.000025)$, a gene with no functional annotation (Supplementary Fig. S6D); and Zm00001d013049 $(P=0.000026)$, encoding an exocyst complex component (EXO84B). Knockout alleles of the Arabidopsis homolog of the latter gene exhibited significantly increased susceptibility to the hemibiotrophic pathogen Phytophthora infestans (Du et al. 2018; Supplementary Fig. S6E). However, given the lack of statistical significance after multiple testing correction, it must be kept in mind that one, several, or all of these genes may represent false-positive associations.

Southern corn rust has long been primarily considered a threat to maize production in tropical and subtropical climates. However, the expected changes in climate are likely to increase the frequency and severity of southern corn rust outbreaks in more temperate production regions (Mueller et al. 2020). While the major resistance locus RPP9 has been incorporated into a number of commercial maize hybrids in the United States (Holland et al. 1998), the breakdown of resistance to southern corn rust conveyed by this locus began to be reported over a decade ago (Brewbaker et al. 2011; Dolezal et al. 2009). While qualitative resistance loci have been largely sourced from tropical maize germplasm (Brewbaker et al. 2011), here we showed that significant quantitative resistance exists 
that could be mapped to specific loci within a set of 689 diverse temperate-adapted maize inbred lines. Given the potential for yield losses of 39 to $50 \%$ from severe and early season southern rust outbreaks and the increasing potential for these outbreaks, phenotyping, genetic, and breeding efforts to ameliorate or at least mitigate potential losses from such outbreaks are clearly needed. A set of 139 lines included in this study originate from expired plant variety proprietary germplasm, representing high-performing genetic backgrounds well adapted to hybrid production in the temperate U.S. Corn Belt (Al Bari 2014). Several of these lines exhibited strong resistance to southern corn rust, including CR1HT, LH54, and PHJ40. These lines may be particularly promising donors of southern corn rust resistance loci for temperate maize breeding programs, as introgressions from these backgrounds are likely to be associated with substantially less yield drag than introgressions directly from tropical maize donor lines.

Data availability statement. The two sets of RNA-seq data used in this study are from Mazaheri et al. (2019), available under NCBI BioProject accession number PRJNA189400, and Hirsch et al. (2014), available under NCBI BioProject accession number PRJNA437324. Resequencing genome sequencing data are from Qiu et al. (2020), available under NCBI BioProject accession number PRJNA661271. The maize hapmap3 genomic data are from Bukowski et al. (2018) and are available at https://datacommons. cyverse.org/browse/iplant/home/shared/commons_repo/curated/Qi_ Sun_Zea_mays_haplotype_map_2018/282_onHmp321. The SNP dataset generated for genome-wide association study is openly available in figshare at https://figshare.com/articles/dataset/WiDiv689_ maf1 het01_vcf_gz/14365544.

\section{ACKNOWLEDGMENTS}

This project was completed utilizing the Holland Computing Center of the University of Nebraska, which receives support from the Nebraska Research Initiative. We thank Marcin Grzybowski for technical support of this work. We also thank Linsey Newton and Addie M. Thompson from Michigan State University for kindly providing the seed for this diversity panel, enabling us to conduct the field experiments described in this study during the 2020 COVID-19 pandemic lockdown.

\section{LITERATURE CITED}

Al Bari, M. A. 2014. Usefulness of expired proprietary (Ex-PVP) maize (Zea mays L.) germplasm for U.S. northern breeding programs. North Dakota State University, Fargo, ND. https://hdl.handle.net/10365/27300

Bates, D., Maechler, M., Bolker, B., Walker, S., Christensen, R. H. B., Singmann, H., Dai, B., Scheipl, F., Grothendieck, G., Green, P., Fox, J., Bauer, A., and Krivitsky, P. N. 2018. Package 'Ime4'. Version 1:17. https://cran.r-project.org/web/packages/lme4/index.html

Berkey, R., Bendigeri, D., and Xiao, S. 2012. Sphingolipids and plant defense/ disease: The "death" connection and beyond. Front. Plant Sci. 3:68.

Bolger, A. M., Lohse, M., and Usadel, B. 2014. Trimmomatic: A flexible trimmer for Illumina sequence data. Bioinformatics 30:2114-2120.

Brewbaker, J. L., Kim, S. K., So, Y. S., Logroño, M., Moon, H. G., Ming, R.-G., Lu, X. W., and Josue, A. D. 2011. General resistance in maize to southern rust (Puccinia polysora underw.). Crop Sci. 51:1393-1409.

Browning, B. L., Zhou, Y., and Browning, S. R. 2018. A one-penny imputed genome from next-generation reference panels. Am. J. Hum. Genet. 103:338-348.

Brunelli, K. R., Silva, H. P., and Camargo, L. E. A. 2002. Mapping of quantitative resistance genes to Puccinia polysora in maize [Mapeamento de genes de resistencia quantitativa a Puccinia polysora em milho]. Fitopatol. Bras. 27:134-140.

Bukowski, R., Guo, X., Lu, Y., Zou, C., He, B., Rong, Z.-Q., Wang, B., Xu, D.-W., Yang, B.-C., Xie, C.-X., Fan, L.-J., Gao, S.-B., Xu, X., Zhang, G.-Y., Li, Y.-G., Jiao, Y.-P., Doebley, J. F., Ross-Ibarra, J., Lorant, A., Buffalo, V., Romay, M. C., Buckler, E. S., Ware, D., Lai, J.-S., Sun, Q., and Xu, Y.-B. 2018. Construction of the third-generation Zea mays haplotype map. Gigascience 7:gix134.

Castelletti, S., Tuberosa, R., Pindo, M., and Salvi, S. 2014. A mite transposon insertion is associated with differential methylation at the maize flowering time QTL vgt1. Genes, Genomes, Genetics 4:805-812.
Chang, C. C., Chow, C. C., Tellier, L. C. A. M., Vattikuti, S., Purcell, S. M., and Lee, J. J. 2015. Second-generation plink: Rising to the challenge of larger and richer datasets. Gigascience 4.

Chávez-Medina, J. A., Leyva-López, N. E., and Pataky, J. K. 2007. Resistance to Puccinia polysora in maize accessions. Plant Dis. 91:1489-1495.

Clouse, S. D. 1996. Molecular genetic studies confirm the role of brassinosteroids in plant growth and development. Plant $\mathrm{J}$.

Corn ipmPIPE. 2020. Southern corn rust (Puccinia polysora map). https:// corn.ipmpipe.org/southerncornrust/

Corwin, J. A., and Kliebenstein, D. J. 2017. Quantitative resistance: more than just perception of a pathogen. Plant Cell 29:655-665.

Cummins, G. B. 1941. Identity and distribution of three rusts of corn. Phytopathology 31:856-857.

David, L., Harmon, A. C., and Chen, S. 2019. Plant immune responses-Fom guard cells and local responses to systemic defense against bacterial pathogens. Plant Signal. Behav. 14:e1588667.

Dolezal, W., Tiwari, K., Kemerait, R., Kichler, J., Sapp, P., and Pataky, J. 2009. An unusual occurrence of southern rust, caused by Rpp 9 -virulent Puccinia polysora, on corn in southwestern Georgia. Plant Dis. 93:676.

Du, Y., Overdijk, E. J., Berg, J. A., Govers, F., and Bouwmeester, K. 2018. Solanaceous exocyst subunits are involved in immunity to diverse plant pathogens. J. Exp. Bot. 69:655-666.

Gage, J. L., Vaillancourt, B., Hamilton, J. P., Manrique-Carpintero, N. C., Gustafson, T. J., Barry, K., Lipzen, A., Tracy, W. F., Mikel, M. A., Kaeppler, S. M., Buell, C. R., and de Leon, N. 2019. Multiple maize reference genomes impact the identification of variants by genome-wide association study in a diverse inbred panel. Plant Genome 12:180069.

Guimarães, R. L., and Stotz, H. U. 2004. Oxalate production by Sclerotinia sclerotiorum deregulates guard cells during infection. Plant Physiol. 136: 3703-3711.

Hansey, C. N., Johnson, J. M., Sekhon, R. S., Kaeppler, S. M., and De Leon, N. 2011. Genetic diversity of a maize association population with restricted phenology. Crop Sci. 51:704-715.

Hirsch, C. N., Foerster, J. M., Johnson, J. M., Sekhon, R. S., Muttoni, G., Vaillancourt, B., Peñagaricano, F., Lindquist, E., Pedraza, M.-A., Barry, K., de Leon, N., Kaeppler, S. M., and Buell, C. R. 2014. Insights into the maize pan-genome and pan-transcriptome. Plant Cell 26:121-135.

Holland, J., Uhr, D., Jeffers, D., and Goodman, M. 1998. Inheritance of resistance to southern corn rust in tropical-by-corn-belt maize populations. Theor. Appl. Genet. 96:232-241.

Howarth, J. R., Fourcroy, P., Davidian, J.-C., Smith, F. W., and Hawkesford, M. J. 2003. Cloning of two contrasting high-affinity sulfate transporters from tomato induced by low sulfate and infection by the vascular pathogen Verticillium dahliae. Planta 218:58-64.

Huang, M., Hayward, J. J., Corey, E., Garrison, S. J., Wagner, G. R., Krotscheck, U., Hayashi, K., Schweitzer, P. A., Lust, G., Boyko, A. R., and Todhunter, R. J. 2017. A novel iterative mixed model to remap three complex orthopedic traits in dogs. PLoS One 12:e0176932.

Jackson-Ziems, T. 2020. Southern rust of corn confirmed in southeast Nebraska. University of Nebraska-Lincoln, Institute of Agriculture and Natural Resources CROPWATCH. https://cropwatch.unl.edu/2019/ southern-rust-corn-confirmed-southeast-nebraska.

Jiang, C., Edmeades, G. O., Armstead, I., Lafitte, H. R., Hayward, M. D., and Hoisington, D. 1999. Genetic analysis of adaptation differences between highland and lowland tropical maize using molecular markers. Theor. Appl. Genet. 99:1106-1119.

Jiao, Y., Peluso, P., Shi, J., Liang, T., Stitzer, M. C., Wang, B., Campbell, M. S., Stein, J. C., Wei, X.-H., Chin, C.-S., Guill, K., Regulski, M., Kumari, S., Olson, A., Gent, J., Schneider, K. L., Wolfgruber, T. K., May, M. R., Springer, N. M., Antoniou, E., McCombie, W. R., Presting, G. G., McMullen, M., Ross-Ibarra, J., Dawe, R. K., Hastie, A., Rank, D. R., and Ware, D. 2017. Improved maize reference genome with single-molecule technologies. Nature 546:524-527.

Jines, M., Balint-Kurti, P., Robertson-Hoyt, L., Molnar, T., Holland, J., and Goodman, M. M. 2007. Mapping resistance to southern rust in a tropical by temperate maize recombinant inbred topcross population. Theor. Appl. Genet. 114:659-667.

Kremling, K. A., Chen, S.-Y., Su, M.-H., Lepak, N. K., Romay, M. C., Swarts, K. L., Lu, F., Lorant, A., Bradbury, P. J., and Buckler, E. S. 2018. Dysregulation of expression correlates with rare-allele burden and fitness loss in maize. Nature 555:520-523.

Kremling, K. A., Diepenbrock, C. H., Gore, M. A., Buckler, E. S., and Bandillo, N. B. 2019. Transcriptome-wide association supplements genomewide association in Zea mays. Genes, Genomes, Genetics 9:3023-3033.

Krishna, P. 2003. Brassinosteroid-mediated stress responses. J. Plant Growth Regul. 22:289-297.

Lawrence, C. J., Dong, Q., Polacco, M. L., Seigfried, T. E., and Brendel, V. 2004. MaizeGDB, the community database for maize genetics and genomics. Nucleic Acids Res. 32:D393-D397. 
Li, H. 2013. Aligning sequence reads, clone sequences and assembly contigs with BWA-MEM. arXiv Preprint. arXiv:1303.3997. https://arxiv.org/abs/1303.3997

Li, D., Liu, Q., and Schnable, P. S. 2021. TWAS results are complementary to and less affected by linkage disequilibrium than GWAS. Plant Physiol. 186:1800-1811.

Lin, H.-Y., Liu, Q., Li, X., Yang, J.-L., Liu, S.-Z., Huang, Y.-L., Scanlon, M. J., Nettleton, D., and Schnable, P. S. 2017. Substantial contribution of genetic variation in the expression of transcription factors to phenotypic variation revealed by eRD-GWAS. Genome Biol. 18:192.

Liu, H., Ren, D., Jiang, L., Li, X., Yao, Y., Mi, L.-M., Chen, W.-L., Mo, A.-W., Jiang, N., Yang, J.-S., Chen, P., Ma, H., Luo, X.-J., and Lu, P.-L. 2020. A natural variation in pleiotropic developmental defects uncovers a crucial role for chloroplast tRNA modification in translation and plant development. Plant Cell 32:2345-2366.

Liu, X., Huang, M., Fan, B., Buckler, E. S., and Zhang, Z. 2016. Iterative usage of fixed and random effect models for powerful and efficient genome-wide association studies. PLoS Genet. 12:e1005767.

Luo, M., Hung, F.-Y., Yang, S., Liu, X., and Wu, K. 2014. Histone lysine demethylases and their functions in plants. Plant Mol. Biol. Report. 32:558-565.

Mazaheri, M., Heckwolf, M., Vaillancourt, B., Gage, J. L., Burdo, B., Heckwolf, S., Barry, K., Lipzen, A., Bastos Ribeiro, C., Kono, T. J. Y., Kaeppler, H. F., Spalding, E. P., Hirsch, C. N., Buell, C. R., de Leon, N., and Kaeppler, S. M. 2019. Genome-wide association analysis of stalk biomass and anatomical traits in maize. BMC Plant Biol. 19:45-17.

McKenna, A., Hanna, M., Banks, E., Sivachenko, A., Cibulskis, K., Kernytsky, A., Garimella, K., Altshuler, D., Gabriel, S., Daly, M., and DePristo, M. A. 2010. The Genome Analysis Toolkit: A MapReduce framework for analyzing next-generation DNA sequencing data. Genome Res. 20:1297-1303.

Mueller, D., Wise, K., and Sisson, A. 2018. Corn disease management-Corn disease loss estimates from the United States and Ontario, Canada-2018. CPN 2007:414-426.

Mueller, D. S., Wise, K. A., Sisson, A. J., Allen, T. W., Bergstrom, G. C., Bissonnette, K. M., Bradley, C. A., Byamukama, E., Chilvers, M. I., Collins, A. A., Esker, P. D., Faske, T. R., Friskop, A. J., Hagan, A. K., Heiniger, R. W., Hollier, C. A., Isakeit, T., Jackson-Ziems, T., Jardine, D. J., Kelly, H. M., Kleczewski, N. M., Koehler, A. M., Koenning, S. R., Malvick, D. K., Mehl, H. L., Meyer, R. F., Paul, P. A., Peltier, A. J., Price, P. P., Robertson, A. E., Roth, G. W., Sikora, E. J., Smith, D. L., Tande, C. A., Telenko, D. E. P., Tenuta, A. U., Thiessen, L. D., and Wiebold, W. J. 2020. Corn yield loss estimates due to diseases in the United States and Ontario, Canada, from 2016 to 2019. Plant Health Prog. 21:238-247.

Paul, M. J., Gonzalez-Uriarte, A., Griffiths, C. A., and Hassani-Pak, K. 2018. The role of trehalose 6-phosphate in crop yield and resilience. Plant Physiol. 177:12-23.

Poland, J. A., and Nelson, R. J. 2011. In the eye of the beholder: the effect of rater variability and different rating scales on QTL mapping. Phytopathology 101:290-298.

Qiu, Y.-J., O’Connor, C., Della Coletta, R., Renk, J. S., Monnahan, P. J., Noshay, J. M., Liang, Z.-K., Gilbert, A., Anderson, S. N., McGaugh, S. E., Springer, N. M., and Hirsch, C. N. 2020. Population level variation of transposable elements in a maize diversity panel. Biorxiv.

Raid, R., Pennypacker, S., and Stevenson, R. 1988. Characterization of Puccinia polysora epidemics in Pennsylvania and Maryland. Phytopathology 78:579-585.

Rhind, D., Waterston, J., and Deighton, F. 1952. Occurrence of Puccinia polysora underw. in West Africa. Nature 169:631.

Rodriguez-Ardon, R., Scott, G. E., and King, S. B. 1980. Maize yield losses caused by southern corn rust. Crop Sci. 20:812-814.

Salvi, S., Tuberosa, R., Chiapparino, E., Maccaferri, M., Veillet, S., van Beuningen, L., Isaac, P., Edwards, K., and Phillips, R. L. 2002. Toward positional cloning of $v g t 1$, a QTL controlling the transition from the vegetative to the reproductive phase in maize. Plant Mol. Biol. 48:601-613.

Schnable, P. S., D. Ware, R. S. Fulton, J. C. Stein, F. Wei, Paternak, S., Liang, C., Zhang, J.-W., Fulton, L., Graves, T. A., Minx, P., Reily, A. D., Courtney, L., Kruchowski, S. S., Tomlinson, C., Strong, C., Delehaunty, K., Fronick, C., Courtney, B., Rock, S. M., Belter, E., Du, F.-Y., Kim, K., Abbott, R. M., Cotton, M., Levy, A., Marchetto, P., Ochoa, K., Jackson, S. M., Gillam, B., Chen, W.-Z., Yan, L., Higginbotham, J., Cardenas, M., Waligorski, J., Applebaum, E., Phelps, L., Falcone, L., Kanchi, K., Thane, T., Scimone, A., Thane, N., Henke, J., Wang, T., Ruppert, J., Shah, N., Rotter, K., Hodges, J., Ingenthron, E., Cordes, M., Kohlberg, S., Sgro, J., Delgado, B., Mead, K., Chinwalla, A., Leonard, S., Crouse, K., Collura, K., Kudrna, D., Currie, J., He, R.-F., Angelova, A., Rajasekar, S., Mueller, T., Lomeli, R., Scara, G., Ko, A., Delaney, K., Wissotski, M., Lopez, G., Campos, D., Braidotti, M., Ashley, E., Golser, W., Kim, H.-R., Lee, S., Lin, J., Dujmic, Z., Kim, W.-J., Talage, J., Zuccolo, A., Fan, C.-Z., Sebastian, A., Kramer, M., Spiegel, L., Nascimento, L., Zutavern, T., Miller, B., Ambroise, C., Muller, S., Spooner, W., Narechania, A., Ren, L.-Y., Wei,
S., Kumari, S., Faga, B., Levy, M. J., McMahan, L., van Buren, P., Vaughn, M. W., Ying, K., Yeh, C.-T., Emrich, S. J., Jia, Y., Kalyanaraman, A., Hsia, A.-P., Barbazuk, W. B., Baucom, R. S., Brutnell, T. P., Carpita, N. C., Chaparro, C., Chia, J.-M., Deragon, J.-M., Estill, J. C., Fu, Y., Jeddeloh, J. A., Han, Y.-J., Lee, H.-R., Li, P.-H., Lisch, D. R., Liu, S.-Z., Liu, Z.-J., Nagel, D. H., McCann, M. C., SanMiguel, P., Myers, A. M., Nettleton, D., Nguyen, J., Penning, B. W., Ponnala, L., Schneider, K. L., Schwartz, D. C., Sharma, A., Springer, N. M., Sun, Q., Wang, H., Waterman, M., Westerman, R., Wolfgruber, T. K., Yang, L.-X., Yu, Y.-S., Zhang, L.-F., Zhou, S.-G., Zhu, Q.-H., Bennetzen, J. L., Dawe, R. K., Jiang, J.-M., Jiang, N., Presting, G.-G., Wessler, S. R., Aluru, S., Martienssen, R. A., Clifton, S. W., McCombie, W. R., Wing, R. A., and Wilson, R. K. 2009. The $b 73$ maize genome: complexity, diversity, and dynamics. Science 326:1112-1115.

Shabalin, A. A. 2012. Matrix eQTL: ultra fast eQTL analysis via large matrix operations. Bioinformatics 28:1353-1358.

Shi, L., Bielawski, J., Mu, J., Dong, H., Teng, C., Zhang, J., Yang, X.-H., Tomishige, N., Hanada, K., Hannun, Y. A., and Zuo, J.-R. 2007. Involvement of sphingoid bases in mediating reactive oxygen intermediate production and programmed cell death in Arabidopsis. Cell Res. 17:1030-1040.

Springer, N. M., Ying, K., Fu, Y., Ji, T.-M., Yeh, C.-T., Jia, Y., Wu, W., Richmond, T., Kitzman, J., Rosenbaum, H., Iniguez, A. L., Barbazuk, W. B., Jeddeloh, J. A., Nettleton, D., and Schnable, P. 2009. Maize inbreds exhibit high levels of copy number variation (CNV) and presence/ absence variation (PAV) in genome content. PLOS Gen.

Storey, H., and Howland, A. K. 1959. Resistance in maize to the tropical American rust fungus, Puccinia polysora. Heredity 13:61-65.

Studer, A., Zhao, Q., Ross-Ibarra, J., and Doebley, J. 2011. Identification of a functional transposon insertion in the maize domestication gene $t b 1$. Nat. Genet. 43:1160-1163.

Swanson-Wagner, R. A., Eichten, S. R., Kumari, S., Tiffin, P., Stein, J., and Springer, N. M. 2010. Pervasive gene content variation and copy number variation in maize and its undomesticated progenitor. Genome Res.

Tsiantis, M. 2011. A transposon in $t b l$ drove maize domestication. Nat. Genet. 43:1048-1050.

Ullstrup, A. 1965. Inheritance and linkage of a gene determining resistance in maize to an American race of Fuccinia polysora. Phytopathology 55:425-428.

Underwood, L. M. 1897. Some new fungi, chiefly from Alabama. Bull. Torrey Bot. Club 24:81.

Wallace, J. G., Zhang, X., Beyene, Y., Semagn, K., Olsen, M., Prasanna, B. M., and Buckler, E. S. 2016. Genome-wide association for plant height and flowering time across 15 tropical maize populations under managed drought stress and well-watered conditions in sub-Saharan Africa. Crop Sci. 56:2365-2378.

Wanlayaporn, K., Authrapun, J., Vanavichit, A., and Tragoonrung, S. 2013. QTL mapping for partial resistance to southern corn rust using RILs of tropical sweet corn. Am. J. Plant Sci. 4:878-889.

Wu, X., Li, N., Zhao, P., He, Y., and Wang, S. 2015. Geographic and genetic identification of $\operatorname{RppS}$, a novel locus conferring broad resistance to southern corn rust disease in China. Euphytica 205:17-23.

Xia, Y., Suzuki, H., Borevitz, J., Blount, J., Guo, Z., Patel, K., Dixon, R. A., and Lamb, C. 2004. An extracellular aspartic protease functions in Arabidopsis disease resistance signaling. EMBO J. 23:980-988.

Yan, J., Tong, T., Li, X., Chen, Q., Dai, M., Niu, F.-F., Yang, M.-F., Deyholos, M. K., Yang, B., and Jiang, Y.-Q. 2018. A novel NAC-type transcription factor, NAC87, from oilseed rape modulates reactive oxygen species accumulation and cell death. Plant Cell Physiol. 59:290-303.

Yin, L., Zhang, H., Tang, Z., Xu, J., Yin, D., Zwang, Z.-W., Yuan, X.-H., Zhu, M.-G., Zhao, S.-H., Li, X.-L., and Liu, X.-L. 2021. rMVP: A memory-efficient, visualization-enhanced, and parallel-accelerated tool for genome-wide association study. Genomics Proteomics Bioinformatics

Zhang, H., Hong, Y., Huang, L., Liu, S., Tian, L., Dai, Y., Cao, Z.-Y., Huang, L.-H., Li, D.-Y., and Song, F.-M. 2016. Virus-induced gene silencing-based functional analyses revealed the involvement of several putative trehalose-6-phosphate synthase/phosphatase genes in disease resistance against Botrytis cinerea and Pseudomonas syringae pv. tomato dc3000 in tomato. Front. Plant Sci. 7:1176.

Zhao, P., Zhang, G., Wu, X., Li, N., Shi, D., Zhang, D.-F., Ji, C.-F., Xu, M.-L., and Wang, S.-C. 2013. Fine mapping of RppP25, a southern rust resistance gene in maize. J. Integr. Plant Biol. 55:462-472.

Zhou, X., and Stephens, M. 2012. Genome-wide efficient mixed-model analysis for association studies. Nat. Genet. 44:821-824

Zhou, X.-G., Liao, H.-C., Chern, M.-S., Yin, J.-J., Chen, Y.-F., Wang, J.-P., Xiaobo, Z., Chen, Z.-X., Yuan, C., Zhao, W., Wang, J., Li, W.-T., He, M., Ma, B.-T., Wang, J.-C., Qin, P., Chen, W.-L., Wang, Y.-P., Liu, J. L., Qian, Y.-W., Wang, W.-M., Wu, X.-J., Li, P., Zhu, L.-H., Li, S.-G., Ronald, C. R., and Chen, X.-W. 2018. Loss of function of a rice TPRdomain RNA-binding protein confers broad-spectrum disease resistance. Proc. Natl. Acad. Sci. USA 115:3174-3179. 